\title{
Association between regulated upon activation, normal T cells expressed and secreted (RANTES) -28C/G polymorphism and asthma risk - A Meta-Analysis
}

\author{
Qiaoqiao Fang ${ }^{1^{*}}$, Furu Wang ${ }^{2^{*}}$, Deyu Zhao ${ }^{\circledR}$ \\ 1. Department of Respiratory Medicine, Nanjing Children's Hospital Affiliated to Nanjing Medical University, Nanjing \\ 210029, China; \\ 2. Department of Epidemiology and Biostatistics, Cancer Center, Nanjing Medical University, Nanjing 210029, China \\ * Contributed equally.
}

$\triangle$ Corresponding author: Dr. Deyu Zhao, Department of Respiratory Medicine, Nanjing Children's Hospital Affiliated to Nanjing Medical University, 72 GuangZhou Rd, Nanjing 210029, China. Tel (Fax): 86-25- 831-17367. E-mail: zhaodeyu98@126.com

Received: 2010.01.15; Accepted: 2010.02.04; Published: 2010.02.10

\begin{abstract}
Regulated upon activation, normal T-cell expressed and secreted (RANTES) is one of the most extensively studied C-C chemokines in allergic inflammation. A growing body of evidence suggests that many cell types present in asthmatic airways have the capacity to generate RANTES, which directly supported the potential role of RANTES in asthma. A number of studies have evaluated the functional polymorphism -28C/G in the RANTES promoter region, which had been found to affect the transcription of the RANTES gene, in relation to asthma susceptibility. However, the results remain conflicting rather than conclusive. This meta-analysis on 1894 asthma cases and 1766 controls for $-28 \mathrm{C} / \mathrm{G}$ from 9 published case-control studies showed that the variant allele -28G was associated with significantly increased risk of asthma (GG+CG vs $C C$ : $O R=I .24,95 \% \mathrm{Cl}=I .08-I .4 I)$ without any between-study heterogeneity.

In the stratified analysis by asthma type, age and ethnicity, we found that the increased asthma risk associated with $-28 \mathrm{G} / \mathrm{C}$ polymorphism was more evident in children (OR=I.24, $95 \% \mathrm{Cl}=1.06-1.45)$, Asian group $(\mathrm{OR}=1.27,95 \% \mathrm{Cl}=1.04-1.56)$ and African group (OR=1.72, $95 \% \mathrm{Cl}=1.07-2.78)$. These results suggest that RANTES -28G/C polymorphism may contribute to asthma development, especially in children and in Asian population. Additional well-designed large studies were required for the validation of this association.
\end{abstract}

Key words: RANTES, polymorphism, susceptibility, asthma, meta-analysis

\section{Introduction}

Asthma is a chronic inflammatory disorder of the airways and is characterized by variable airflow obstruction and bronchial hyper responsiveness (BHR) [1]. The prevalence and severity of asthma have been increasing in many countries, the trends being most pronounced for children and adolescents [2]. The pathogenesis and etiology of asthma is very complex and not fully understood, although an interaction of multiple genetic loci and a variety of environmental factors have been suggested as important determinants of this disease [3,4]. It was reported that asthma is a disease with a strong genetic predisposition, and the recent increase in asthma cases seems to be triggered by increases in environmental 
exposures in previously unaffected but genetically susceptible individuals [5]. However, different genetic background individuals in the same environmental exposures showed different susceptibility to asthma, which indicated that genetic factors may play an important role in the pathogenesis of asthma.

Regulated upon activation, normal T-cell expressed and secreted (RANTES), which generated by $T$ lymphocyte, is one of the most extensively studied C-C chemokines in allergic inflammation[6]. RANTES is likely to be important in airway inflammation because blocking antibodies to RANTES inhibit airway inflammation in a murine model of allergic airway disease [7]. A growing body of evidence suggests that many cell types present in asthmatic airways, such as $\mathrm{T}$ cells, platelets, macrophages, endothelial cells, fibroblasts, epithelial cells, and mast cells, have the capacity to generate RANTES [8], which directly supported the potential role of RANTES in asthma.

The gene encoding RANTES is located on chromosome 17q11.2-q12 [9] that has been shown to be in linkage with asthma in several studies $[10,11]$. The $-28 \mathrm{C} / \mathrm{G}$ polymorphism in the RANTES promoter region had been found to affect the transcription of the RANTES gene. In human cell lines, the $-28 \mathrm{G}$ was shown to increase promoter activity of RANTES in comparison with the more frequent $-28 \mathrm{C}$, suggesting that the polymorphism can increase RANTES expression in the human body [12]. Therefore, it's reasonable to hypothesize that the RANTES -28C/G polymorphism may functionally relate to the risk of asthma.

A number of molecular epidemiological studies have been conducted to examine the association between RANTES -28C/G polymorphism and asthma susceptibility [1,13-20], but the results remain inconsistent. To estimate the overall risk of RANTES $-28 \mathrm{C} / \mathrm{G}$ associated with asthma risk and to quantify the potential between-study heterogeneity, we conducted a meta-analysis on 9 published case-control studies with 1894 asthma cases and 1766 controls for $-28 \mathrm{C} / \mathrm{G}$.

\section{Materials and Methods}

Identification and Eligibility of Relevant Studies. Eligible studies were identified by searching the electronic literature PubMed and EMBASE for relevant reports (last search update February 2009, using the search terms "RANTES", "polymorphisms" and "asthma"; "CCL5", "polymorphisms" and "asthma"). Additional studies were identified by hands-on searches from references of original studies or review articles on this topic. Searching was performed in duplicate by two independent reviewers
(Q.F. and F.W.). Results were limited to English language papers and Chinese language papers.

Inclusion criteria. We attempted to include all the case-control studies published to date on the association between RANTES -28C/G polymorphism and asthma risk. Human studies, regardless of sample size, were included if they met the following criteria:

(1) RANTES polymorphism at $-28 \mathrm{C} / \mathrm{G}$ were determined.

(2) Studies were case-control design (retrospective or nested case-control).

(3) Each genotype frequency was reported, and there was sufficient information for extraction of data.

(4) If studies had partly overlapped subjects, only the one with a larger and/or latest sample size was selected for the analysis.

Data Extraction. Two reviewers (Q.F. and F.W.) independently extracted data and reached a consensus on all of the items. Data extracted from these articles included the first author's name, year of publication, country of origin, ethnicity, type of asthma, number of cases and controls, and the minor allele frequency in controls.

Meta-Analysis. The risk of asthma associated with $-28 \mathrm{C} / \mathrm{G}$ RANTES was estimated for each study by odds ratio (OR) with $95 \%$ confidence intervals ( $95 \% \mathrm{CI})$. For all studies, we evaluated the risk of the variant genotypes (GG/CG), compared with the wild-type genotype (CC). Then we calculated the ORs of the polymorphism (GG+CG versus $\mathrm{CC}$, and $\mathrm{GG}$ versus $(G+C C)$, using both dominant and recessive genetic models of the variant $G$ allele. In addition, we conducted stratification analysis by asthma types, age and ethnicity. As a result, 2 case-control studies of asthma type (777 cases and 495 controls); 9 case-control studies of age (1894 cases and 1766 controls) and 9 case-control studies of ethnicity (1894 cases and 1766 controls) were available for this meta-analysis. The $\chi^{2}$-based $Q$ statistic test was used for the assessment of heterogeneity, and it was considered significant for $P<0.01$. We used the fixed-effects model and the random-effects model based on the Mantel-Haenszel method and the DerSimonian and Laird method, respectively, to combine values from each of the studies. When the effects were assumed to be homogenous, the fixed-effects model was then used; otherwise, the random-effects model was more appropriate. We also computed the power of the selected studies by using the DSTPLAN4.2 software, in order to assess the probability of detecting an association between RANTES $-28 \mathrm{C} / \mathrm{G}$ polymorphism and asthma at the 0.05 level of 
significance, assuming a genotypic risk of 2.0 and 1.5. The Egger's test and inverted funnel plots were utilized to provide diagnosis of publication bias (Linear regression analysis, ref. [21]). All analysis was done by using the Statistical Analysis System software (v.9.1.3, SAS Institute, Cary, NC) and Review Manage (v.4.2). All the $P$ values were two-sided.

\section{Results}

The selected study characteristics are listed in Table 1. All studies indicated that the distributions of the $-28 \mathrm{C} / \mathrm{G}$ polymorphism's genotypes in the controls were both consistent with Hardy-Weinberg equilibrium except for two studies $[18,19]$. The minor G allele frequency (MAF) was 0.14 for Asian studies, 0.06 for African, while around 0.03 for Caucasian, respectively.

Variant genotypes of RANTES -28C/G polymorphisms were associated with an increased asthma risk in different genetic models. As shown in Table 2, both the variant homozygote (-28GG) and heterozygote $(-28 \mathrm{CG})$ were associated with a significantly increased risk of asthma (GG versus CC: $\mathrm{OR}=1.98$, 95\% CI=1.24-3.16; $\mathrm{P}=0.29$ for heterogeneity test; CG versus $C C$ : $O R=1.25,95 \% C I=1.04-1.50 ; P=0.60$ for heterogeneity test), compared with wild-type homozygote (-28CC). Significant main effects were also observed in the dominant genetic model (GG+CG versus $C C$ : $O R=1.24,95 \% C I=1.08-1.41 ; P=0.47$ for heterogeneity test; Table 2 and Figure 1).

We further performed stratified analysis according to asthma type (atopic asthma and non-atopic asthma), age (children and adult) and ethnicity (Asian and Caucasian and African ethnicity), and the estimate results were presented in Table 3 . As shown in the table, we found that the increased asthma risk associated with $-28 \mathrm{G} / \mathrm{C}$ polymorphism was more evident in children $(\mathrm{OR}=1.24$, $95 \% \mathrm{CI}=1.06-1.45, P=0.39$ for heterogeneity test), Asian group (OR=1.27, 95\% CI=1.04-1.56, $P=0.48$ for heterogeneity test) and African group (OR=1.72, $95 \% \mathrm{CI}=1.07-2.78, P=0.23$ for heterogeneity test).

We used Funnel plot and Egger's test to access the publication bias of literatures. As shown in Fig. 2, the shape of the funnel plots seemed symmetrical in the dominant genetic model for the $-28 \mathrm{C} / \mathrm{G}$, suggesting that there was no publication bias. Egger's test was used to provide statistical evidence. As a result, no publication bias was observed for $-28 \mathrm{C} / \mathrm{G}(\mathrm{t}=2.30$, $\mathrm{P}=0.92)$.

Table I. Characteristics of published studies included in the meta-analysis.

\begin{tabular}{|c|c|c|c|c|c|c|c|c|}
\hline \multirow[t]{2}{*}{ Author[ref*) } & \multirow[t]{2}{*}{ Year } & \multirow{2}{*}{$\begin{array}{l}\text { Origin } \\
\text { (Ethnicity) }\end{array}$} & \multirow{2}{*}{$\begin{array}{l}\text { Asthma group } \\
\text { (CC/CG/GG) }\end{array}$} & \multirow{2}{*}{$\begin{array}{l}\text { Control group } \\
\text { (CC/CG/GG) }\end{array}$} & \multirow[t]{2}{*}{ HWE } & \multirow{2}{*}{$\begin{array}{l}\text { MAF } \\
\text { in controls }\end{array}$} & \multicolumn{2}{|c|}{ Power $(\%) \dagger$} \\
\hline & & & & & & & OR $>1.5$ & OR $>2.0$ \\
\hline Szalai C[13]\& & 2001 & $\begin{array}{l}\text { Hungary } \\
\text { (Caucasian) }\end{array}$ & $144 / 16 / 0$ & $284 / 19 / 0$ & 0.573 & 0.03 & 11.9 & 29.7 \\
\hline Hizawa N[14] & 2002 & $\begin{array}{l}\text { Japan } \\
\text { (Asian) }\end{array}$ & $216 / 70 / 12$ & $243 / 62 / 6$ & 0.387 & 0.12 & 41.7 & 88.2 \\
\hline Yao TC[15] & 2003 & $\begin{array}{l}\text { China(Taiwan) } \\
\text { (Asian) }\end{array}$ & $134 / 39 / 9$ & $83 / 23 / 1$ & 0.666 & 0.12 & 21.3 & 55.3 \\
\hline Wang LJ[16] & 2004 & $\begin{array}{l}\text { China } \\
\text { ( Asian) }\end{array}$ & $65 / 31 / 4$ & $72 / 17 / 1$ & 0.998 & 0.11 & 15.5 & 39.7 \\
\hline Huang JL [17] & 2005 & $\begin{array}{l}\text { China(Taiwan) } \\
\text { (Asian) }\end{array}$ & $189 / 53 / 9$ & $83 / 23 / 1$ & 0.666 & 0.12 & 23.3 & 59.8 \\
\hline Moissidis I[18] & 2005 & $\begin{array}{l}\text { United States } \\
\text { (African-American) }\end{array}$ & $59 / 2 / 0$ & $129 / 0 / 0$ & 0.000 & 0.00 & $\mathrm{NA}^{\#}$ & $\mathrm{NA}^{\#}$ \\
\hline Lachheb J[19] & 2007 & $\begin{array}{l}\text { Tunisia } \\
\text { ( African) }\end{array}$ & $163 / 35 / 12$ & $190 / 29 / 5$ & 0.005 & 0.09 & 25.8 & 65.9 \\
\hline Muro M[20] & 2008 & $\begin{array}{l}\text { Spain } \\
\text { (Caucasian) }\end{array}$ & $289 / 17 / 0$ & $228 / 14 / 0$ & 0.643 & 0.03 & 14.1 & 36.7 \\
\hline Sohn MH[1] & 2008 & $\begin{array}{l}\text { Korea } \\
\text { (Asian) }\end{array}$ & $218 / 93 / 15$ & $174 / 66 / 13$ & 0.050 & 0.19 & 52.1 & 94.6 \\
\hline
\end{tabular}

* The ref was referred to the reference numbers in this study.

$\&$ data from the same source, so selected by the latest sample size.

\# NA: Not available.

t Power was calculated by the DSTPLAN4.2 software with MAF in controls as the frequency of risk factor, OR was selected 1.5 and 2.0 as the relative risk and $\mathrm{a}=0.05$ as the significance. 
Table 2. Summary ORs of the RANTES $-28 \mathrm{C} / \mathrm{G}$ polymorphism and asthma risk.

\begin{tabular}{|c|c|c|c|c|c|}
\hline Comparison & No. of Cases & No. of Controls & OR & $95 \% \mathrm{CI}$ & $P^{*}$ \\
\hline CG vs CC & 1833 & 1739 & 1.25 & $1.04-1.50$ & 0.60 \\
\hline GG vs CC & 1538 & 1513 & 1.98 & $1.24-3.16$ & 0.29 \\
\hline GG vs $C G+C C$ & 1894 & 1766 & 1.88 & $1.18-3.00$ & 0.30 \\
\hline $\mathrm{CG}+\mathrm{GG}$ vs $\mathrm{CC}$ & 1894 & 1766 & 1.24 & $1.08-1.41$ & 0.47 \\
\hline
\end{tabular}

* Test for heterogeneity. Fixed-effects model was used when P value for heterogeneity test > 0. 01; otherwise, random-effects model was used.

Table 3. Association between asthma risk and the RANTES - $28 \mathrm{C} / \mathrm{G}$ polymorphisms, stratified by asthma type, age and ethnicity.

\begin{tabular}{|c|c|c|c|c|c|c|}
\hline Stratified variable & $\begin{array}{l}\text { Studies of } \\
\text { available }\end{array}$ & $\begin{array}{l}\text { No. of } \\
\text { Cases }\end{array}$ & $\begin{array}{l}\text { No. of } \\
\text { Controls }\end{array}$ & OR\# & $95 \% \mathrm{CI}$ & $\mathrm{P}^{*}$ \\
\hline \multicolumn{7}{|l|}{ asthma type } \\
\hline atopic & {$[1,20]$} & 577 & 495 & 1.04 & $0.75-1.44$ & 0.81 \\
\hline non-atopic & {$[1,20]$} & 200 & 495 & 1.15 & $0.69-1.90$ & 0.61 \\
\hline \multicolumn{7}{|l|}{ age } \\
\hline children & {$[1,13,15-17,19]$} & 1229 & 1084 & 1.24 & $1.06-1.45$ & 0.39 \\
\hline adult & {$[14,18,20]$} & 665 & 682 & 1.24 & $0.96-1.60$ & 0.29 \\
\hline \multicolumn{7}{|l|}{ ethnicity } \\
\hline Asian & {$[1,14-17]$} & 1157 & 868 & 1.27 & $1.04-1.56$ & 0.48 \\
\hline Caucasian & {$[13,20]$} & 466 & 545 & 1.27 & $0.77-2.11$ & 0.22 \\
\hline African & {$[18,19]$} & 271 & 353 & 1.72 & $1.07-2.78$ & 0.23 \\
\hline
\end{tabular}

\# The OR was obtained in dominant genetic model.

* Test for heterogeneity. Fixed-effects model was used when P value for heterogeneity test >0.10; otherwise, random-effects model was used.

$\$$ Studies of available was referred to the reference resource of each stratified variable, which data was available.

\section{RANTES $-28 \mathrm{C} / \mathrm{G}$ polymorphism and asthma risk}

\section{CG+GG vs CC}

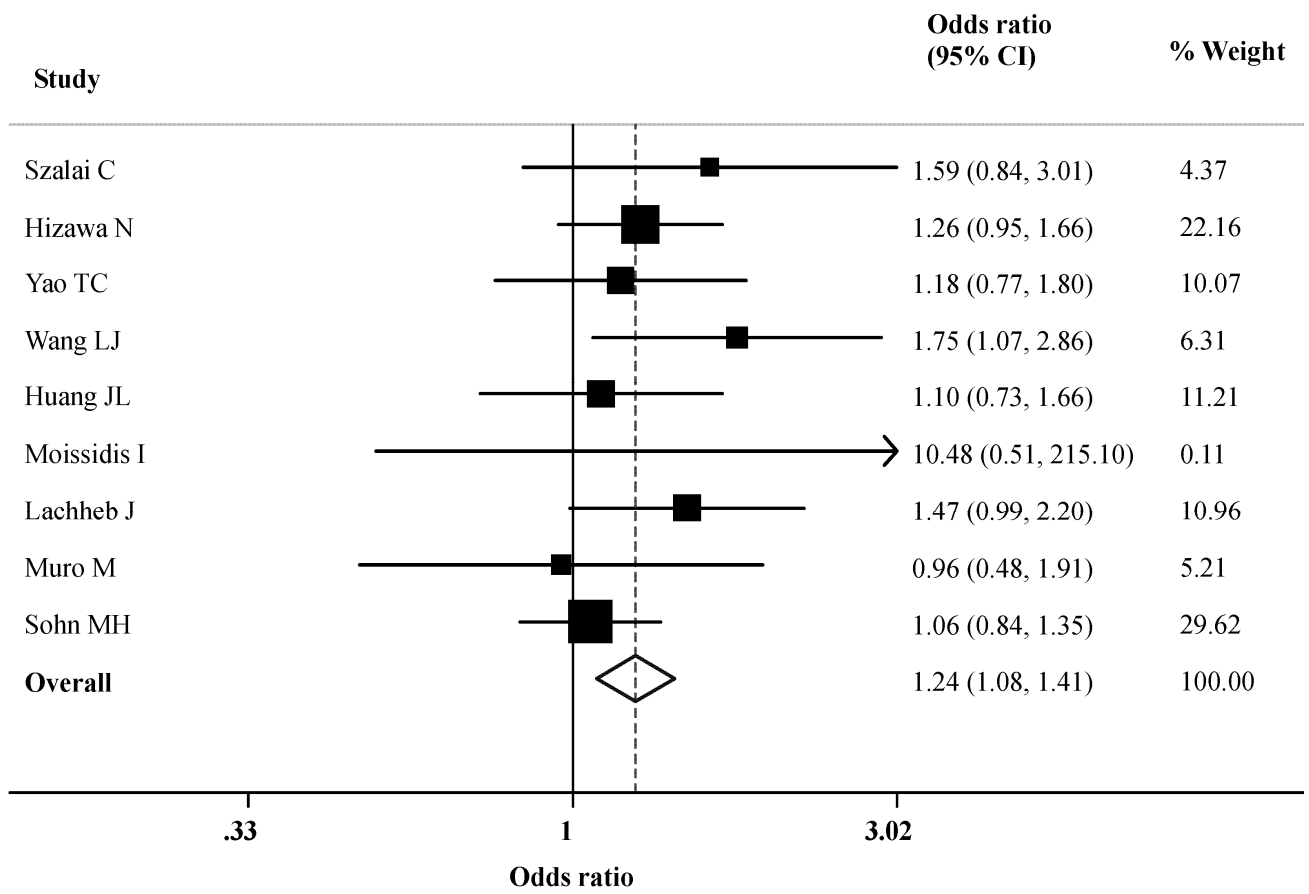

Figure I. ORs (log scale) of asthma associated with RANTES -28C/G for the CG+GG genotypes, compared with the CC genotype. 


\section{$-28 \mathrm{C} / \mathrm{G}$ \\ CG+GG vs $C C$}

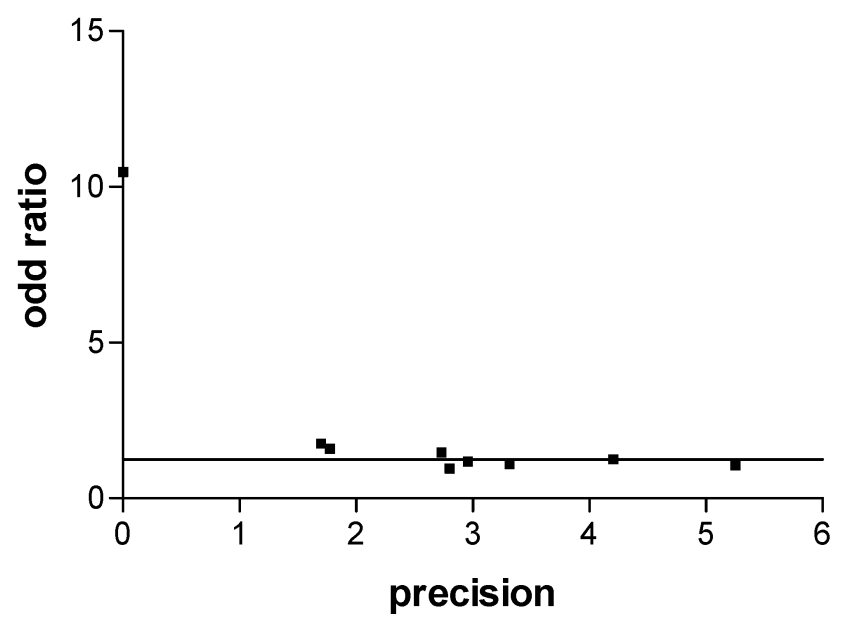

Figure 2. Funnel plot analysis to detect publication bias in asthma. Each point represents a separate study for the indicated association. For each study, the OR is plotted on a logarithmic scale against the precision (the reciprocal of the SE).

\section{Discussion}

Regulated upon activation, normal T-cell expressed and secreted (RANTES) is a C-C chemokine that has been shown to be a potent chemoattractant for $\mathrm{T}$ cells, eosinophils, basophils, monocyte/macrophages, and mast cells [22]. It has been shown that RANTES induces recruitment of eosinophils and their up regulation into the airways of asthmatic patients causing tissue damage [23-25]. Both atopic asthma and nonatopic asthma are associated with increased levels of RANTES in bronchoalveolar lavage fluid [26] and bronchial mucosal expression of RANTES (together with eosinophil-active cytokines such as interleukin-5, granulocyte macrophage colony-stimulating factor, and interleukin-3), which contributes to the bronchial mucosal accumulation of activated eosinophils [27]. Mutations in the proximal promoter region of the RANTES gene may affect transcriptional activity and sub-sequently RANTES over expression in lung cells [19]. It was reported that over expression of RANTES causes increased neutrophils and eosinophils infiltration into the airways, which are considered a prominent feature of airway inflammation [28]. This inflammation is resulting mainly from recruitment of eosinophils in a manner that correlates with asthma severity [29]. Therefore, as one of the C-C chemokines, the RANTES polymorphisms necessarily resulted into the level of eosinophils elevating correspond, and then increased the individual risk of suffering from asthma.

The expression of RANTES is differentially regulated in various cell types, and a large number of putative cis-acting elements have been described in the promoter region by Nelson et al. [6], who subsequently also identified a novel regulatory region critical for its expression [30]. The RANTES -28C/G polymorphism was found to be adjacent to the NF- $\mathrm{K}$ $\mathrm{B}$ binding site, which is a potent inducer of RANTES expression [31]. It has also been reported that the -28G allele elevates promoter activity and increase RANTES protein expression in the functional study [12]. In addition, Hizawa et al. [14] suggested that mononuclear cells from subjects who carried the -28G allele produced significantly greater levels of RANTES protein than cells from subjects who did not carry this allele. Thus, it is reasonable to hypothesize that the $-28 \mathrm{C} / \mathrm{G}$ polymorphism with higher activity of RANTES may play more important role in asthma risk.

In the present meta-analysis on the association between RANTES -28C/G polymorphism and risk of asthma, we found that the variant $-28 \mathrm{G}$ alleles could significantly increase the risk of asthma, which is consistent with the hypothesis from previous studies that the $-28 \mathrm{C} / \mathrm{G}$ polymorphism with higher activity of RANTES may be more important in asthma risk, although the association was not significantly evident in most studies individually. In addition, in stratified analysis, we observed that the association between $-28 \mathrm{C} / \mathrm{G}$ and risk of asthma was remained significant in Asian and African population. The different effect of ethnicity may result from several reasons such as: less numbers of available studies for stratified variable, which may result into poor statistic power; different genetic background and environmental exposures, which may contribute to ethnic difference. In addition, it is worth emphasizing that the $-28 \mathrm{C} / \mathrm{G}$ polymorphism was contributed to the increase of asthma susceptibility in children, which may helpful to understand the pathogenesis of children's asthma. Furthermore, small numbers of individuals and inconsistent stratification standards in environmental exposures and genotypes by the published studies limited our statistic power to fully investigate the gene-environment interaction.

In spite of this, our meta-analysis shares some 
key advantages in several aspects. First, substantial number of cases and controls were pooled from different studies, which significantly increased statistical power of the analysis than each individual study. Second, the quality of case-control studies included in current meta-analysis was good and met our inclusion criterion. Third, we did not detect any publication bias indicating that the whole pooled result should be unbiased.

In conclusion, this meta-analysis of 9 case-control studies provided evidence that the RANTES -28C/G polymorphism was significantly associated with increased risk of asthma, especially in children. Further well-designed large studies, particularly referring to gene-gene and gene-environment interactions are warranted to confirm the real contribution of RANTES $-28 \mathrm{C} / \mathrm{G}$ polymorphism to asthma susceptibility.

\section{Acknowledgement}

This work was supported in part by Nanjing Medical scientific and technological development-funded projects (ZKX0306).

\section{Conflict of Interest}

The authors have declared that no conflict of interest exists.

\section{References}

1. Sohn MH, Kim SH, Kim KW, et al. Rantes gene promoter polymorphisms are associated with bronchial hyperresponsiveness in korean children with asthma. Lung. 2008; 186: 37-43.

2. Weiss ST. Epidemiology and heterogeneity of asthma. Ann Allergy Asthma Immunol. 2001; 87: 5-8.

3. Sengler C, Lau S, Wahn U, et al. Interactions between genes and environmental factors in asthma and atopy: New developments. Respir Res. 2002; 3: 7.

4. Maddox L, Schwartz DA. The pathophysiology of asthma. Annu Rev Med. 2002; 53: 477-98.

5. Koppelman GH, Stine OC, Xu J, et al. Genome-wide search for atopy susceptibility genes in dutch families with asthma. J Allergy Clin Immunol. 2002; 109: 498-506.

6. Nelson PJ, Kim HT, Manning WC, et al. Genomic organization and transcriptional regulation of the rantes chemokine gene. J Immunol. 1993; 151: 2601-12.

7. Lukacs NW, Strieter RM, Warmington K, et al. Differential recruitment of leukocyte populations and alteration of airway hyperreactivity by c-c family chemokines in allergic airway inflammation. J Immunol. 1997; 158: 4398-404.

8. Teran LM, Davies DE. The chemokines: Their potential role in allergic inflammation. Clin Exp Allergy. 1996; 26: 1005-19.

9. Donlon TA, Krensky AM, Wallace MR, et al. Localization of a human t-cell-specific gene, rantes (d17s136e), to chromosome 17q11.2-q12. Genomics. 1990; 6: 548-53.
10. A genome-wide search for asthma susceptibility loci in ethnically diverse populations. The collaborative study on the genetics of asthma (csga). Nat Genet. 1997; 15: 389-92.

11. Dizier MH, Besse-Schmittler C, Guilloud-Bataille $M$, et al. Genome screen for asthma and related phenotypes in the french egea study. Am J Respir Crit Care Med. 2000; 162: 1812-18.

12. Liu H, Chao D, Nakayama EE, et al. Polymorphism in rantes chemokine promoter affects hiv-1 disease progression. Proc Natl Acad Sci U S A. 1999; 96: 4581-85.

13. Szalai C, Kozma GT, Nagy A, et al. Polymorphism in the gene regulatory region of $\mathrm{mcp}-1$ is associated with asthma susceptibility and severity. J Allergy Clin Immunol. 2001; 108: 375-81.

14. Hizawa N, Yamaguchi E, Konno S, et al. A functional polymorphism in the rantes gene promoter is associated with the development of late-onset asthma. Am J Respir Crit Care Med. 2002; 166: 686-90.

15. Yao TC, Kuo ML, See LC, et al. The rantes promoter polymorphism: A genetic risk factor for near-fatal asthma in chinese children. J Allergy Clin Immunol. 2003; 111: 1285-92.

16. Wang LJ, Li YR, Chen JH, et al. polymorphism of regulated upon activation, normal $t$ cell expressed and secreted promoter region -28 position in chinese allergic asthmatic children. Zhonghua Jie He He Hu Xi Za Zhi. 2004; 27: 394-7.

17. Huang JL. Asthma severity and genetics in taiwan. J Microbiol Immunol Infect. 2005; 38: 158-63.

18. Moissidis I, Chinoy B, Yanamandra K, et al. Association of il-13, rantes, and leukotriene c4 synthase gene promoter polymorphisms with asthma and/or atopy in african americans. Genet Med. 2005; 7: 406-10.

19. Lachheb J, Chelbi H, Hamzaoui K, et al. Association between rantes polymorphisms and asthma severity among tunisian children. Hum Immunol. 2007; 68: 675-80.

20. Muro M, Marin L, Torio A, et al. Ccl5/rantes chemokine gene promoter polymorphisms are not associated with atopic and nonatopic asthma in a spanish population. Int J Immunogenet. 2008; 35: 19-23.

21. Egger M, Davey Smith G, Schneider $M$, et al. Bias in meta-analysis detected by a simple, graphical test. BMJ. 1997; 315: 629-34.

22. Baggiolini $M$, Dahinden CA. Cc chemokines in allergic inflammation. Immunol Today. 1994; 15: 127-33.

23. Alam R, Stafford $S$, Forsythe $P$, et al. Rantes is a chemotactic and activating factor for human eosinophils. J Immunol. 1993; 150: 3442-8.

24. Schall TJ, Bacon $\mathrm{K}$, Toy $\mathrm{KJ}$, et al. Selective attraction of monocytes and $t$ lymphocytes of the memory phenotype by cytokine rantes. Nature. 1990; 347: 669-71.

25. Kuna $\mathrm{P}$, Reddigari SR, Schall TJ, et al. Rantes, a monocyte and $\mathrm{t}$ lymphocyte chemotactic cytokine releases histamine from human basophils. J Immunol. 1992; 149: 636-42.

26. Alam R, York J, Boyars $M$, et al. Increased mcp-1, rantes, and mip-1alpha in bronchoalveolar lavage fluid of allergic asthmatic patients. Am J Respir Crit Care Med. 1996; 153: 1398-404.

27. Humbert M, Ying S, Corrigan C, et al. Bronchial mucosal expression of the genes encoding chemokines rantes and mcp-3 in symptomatic atopic and nonatopic asthmatics: Relationship to the eosinophil-active cytokines interleukin (il)-5, granulocyte macrophage-colony-stimulating factor, and il-3. Am J Respir Cell Mol Biol. 1997; 16: 1-8.

28. Pan ZZ, Parkyn L, Ray A, et al. Inducible lung-specific expression of rantes: Preferential recruitment of neutrophils. Am J Physiol Lung Cell Mol Physiol. 2000; 279: L658-66.

29. Carroll N, Cooke C, James A. The distribution of eosinophils and lymphocytes in the large and small airways of asthmatics. Eur Respir J. 1997; 10: 292-300. 
30. Nelson PJ, Ortiz BD, Pattison JM, et al. Identification of a novel regulatory region critical for expression of the rantes chemokine in activated $t$ lymphocytes. J Immunol. 1996; 157: 1139-48.

31. Moriuchi H, Moriuchi M, Fauci AS. Nuclear factor-kappa b potently up-regulates the promoter activity of rantes, a chemokine that blocks hiv infection. J Immunol. 1997; 158: 3483-91. 